\title{
Novas Tecnologias para Educação à Distância - NTEAD
}

\author{
Tania R. Garbin ${ }^{1}$, Carlos A. Dainese ${ }^{1}$, Luciano B. Oliveria ${ }^{1}$, Máximo E. Martins ${ }^{1}$ \\ ${ }^{1}$ Universidade Federal de Ouro Preto - UFOP \\ \{trgarbin,cdainese,luciano\}@cead.ufop.br, maximomartins@gmail.com
}

\begin{abstract}
The Group New Technologies for Distance Education - NTEAD began in 2008 and is linked to the Federal University of Ouro Preto - UFOP. It has aim to promote study of augmented and virtual reality, systems for interaction and communication, studies of technology and pedagogical practices and procedures for processes and management.
\end{abstract}

Resumo. O Grupo Novas Tecnologias para Educação à Distância - NTEAD, teve inicio em 2008 e está vinculado a Universidade Federal de Ouro Preto UFOP. Tem como objetivo central o desenvolvimento de estudos de realidade aumentada e virtual, sistema de comunicação e interação, estudo da tecnologia e das práticas pedagógicas e processos e procedimentos de gestão.

Grupo Tecnologia para Educação à Distância - NTEAD foi cadastrado em $2008 \mathrm{com}$ o objetivo de organizar, sistematizar e planejar as ações de pesquisa e educação envolvendo realidade aumentada, realidade virtual, sistemas de web e de videoconferência e ambientes de aprendizagem. O grupo está vinculado à Universidade Federal de Ouro Preto - UFOP, sendo as atividades de pesquisa e ensino realizados no Centro de Educação Aberta e a Distância - CEAD. As linhas de pesquisa estão relacionadas à tecnologia e sua relação com: Currículo e as Práticas Pedagógicas; o Design Instrucional e Laboratórios Virtuais; os Processos de Comunicação e Interação e a Tecnologia para Gestão de Ambientes Educacionais e Gestão Pública.

Os trabalhos do Grupo estão direcionados para o estudo, o desenvolvimento, a gestão e à avaliação de ambientes avançados de Educação, de Educação a Distância (EAD) e de Gestão Pública, incluindo a infraestrutura e aplicações. São abordados os aspectos tecnológicos, computacionais, comportamentais, culturais, pedagógicos, de gestão e de avaliação voltados para os desenvolvedores, professores, tutores, estudantes e gestores. O Grupo multidisciplinar é composto por 23 pesquisadores, técnicos e alunos.

Entre 2008 a 2013 as ações visaram à aquisição e a implantação a infraestrutura tecnológica do CEAD/UFOP, softwares, os laboratórios de informática, salas de produções e edição de vídeo, videoconferência. Foi desenvolvida a integração entre o sistema acadêmico com a AVA Moodle, o sistema de cadastramento e de controle de tutoria, os sistemas de gestão acadêmico e administrativo de cursos de graduação e pósgraduação. Atualmente estão em desenvolvimento estudos relacionados à tecnologia para inclusão educacional e social, avaliação de sistemas para comunicação e interação, sistemas para aprendizagem baseada em projeto e automação de controle de notas. Considerando os temas discutidos pelas linhas de pesquisa e a produção no período de cinco anos, avaliamos que o NTEAD está contribuindo para a área de informática na educação. 